\title{
AFOXÉ FILHOS DE ZAZE: MÚSICA INTERCULTURAL CONSTRUINDO UM LETRAMENTO IDEOLÓGICO
}

\author{
Jailson de Lima Silva ${ }^{1}$ \\ Flávia Maria de Brito Pedrosa Vasconcelos ${ }^{2}$
}

\section{Resumo}

O presente trabalho resulta de uma pesquisa de cunho etnográfico sobre letramento em uma perspectiva intercultural e tem como recorte a análise de algumas partes das letras das músicas do repertório do bloco Afoxé Filhos de Zaze, que faz parte de um estudo mais ampliado das práticas de letramento. Parte-se do pressuposto de que no ambiente social da música existe uma relação mediada pela escrita e a leitura que cumpre uma função social dentro de um determinado contexto cultural. Desse modo, as letras das músicas podem ser analisadas partindo do modelo de letramento ideológico (STREET, 2014), como letramento local não legitimado, uma prática social específica do grupo, que divulga, por intermédio da música, a cultura dos povos de origem negra, contribuindo para uma ação política do grupo no enfrentamento de preconceitos, sobretudo, de etnia e de religião.

Palavras-chave: Letramento. Interculturalidade. Música. Cultura negra. Afoxé.

\section{AFOXÉ CHILDREN OF ZAZE: INTERCULTURAL MUSIC BUILDING AN IDEOLOGICAL LITERACY}

The present work results from an ethnographic research on literacy in an intercultural perspective and presents parts of an analysis of the lyrics and repertoire of a carnival group called Afoxé Filhos de Zaze. The work is part of a larger study of the group's literacy practices. It is assumed that in the social environment of music there is a relationship mediated by writing and reading that fulfills a social function within a given cultural context. In this way, the lyrics can be analyzed based on the ideological literacy model (STREET, 2014), as a non-legitimized local literacy, a group-specific social practice that disseminates, through music, the culture of people of black origin,

\footnotetext{
${ }^{1}$ Mestrando do Programa de Pós-Graduação em Educação, Cultura e Territórios Semiáridos - PPGESA. Universidade do Estado da Bahia - UNEB.

${ }^{2}$ Docente orientadora do Programa de Pós-Graduação em Educação, Cultura e Territórios Semiáridos PPGESA. Universidade do Estado da Bahia - UNEB. Docente efetiva do Colegiado de Artes Visuais. Universidade Federal do Vale do São Francisco - UNIVASF.
} 
contributing to the group's political action in confronting prejudices, especially of ethnicity and religion.

Keywords: Literacy. Interculturality. Music. Black culture. Afoxé.

\section{AFOXÉ FHIJOS DE ZAZE: MÚSICA INTERCULTURAL CONSTRUYENDO UNA LETRA IDEÓLOGICA}

\section{Resumen}

El presente trabajo es el resultado de una investigación etnográfica sobre alfabetización en una perspectiva intercultural y tiene como corte el análisis de algunas partes de la letra del repertorio de Afoxé Filhos de Zaze, que es parte de un estudio más amplio de las prácticas de alfabetización Se supone que en el entorno social de la música existe una relación mediada por la escritura y la lectura que cumple una función social dentro de un determinado contexto cultural. De esta manera, las letras pueden analizarse en función del modelo de alfabetización ideológica (STREET, 2014), como alfabetización local no legitimada, una práctica social específica del grupo que difunde, a través de la música, la cultura de las personas de origen negro, contribuyendo a la acción política del grupo para enfrentar los prejuicios, especialmente de etnia y religión.

Palabras clave: Letrado. Interculturalidad. Música. Cultura negra. Afoxé.

\section{Introdução}

Este artigo resulta de uma pesquisa de cunho etnográfico sobre letramento em uma perspectiva intercultural, tendo como objeto de análise as letras das músicas que compõem o repertório do bloco carnavalesco de Juazeiro (BA), Afoxé Filhos de Zaze, considerando-as como parte de eventos de letramento relevantes na prática da comunicação itnercultural. As letras das músicas podem ser analisadas com base no modelo de letramento ideológico de Street (1984), ou seja, como uma prática social específica do grupo que possibilita divulgar, por intermédio de eventos de letramento, a cultura dos povos de origem negra, contribuindo para o enfrentamento de preconceitos, sobretudo, de etnia e religião.

Embora os conceitos de práticas e eventos de letramentos estejam intimamente relacionados e interdependentes, nesse espaço específico criado pelo Afoxé Filhos de Zaze, consideramos como práticas de letramento, a escrita e a leitura das músicas 
compostas e cantadas pelo grupo e como eventos de letramentos os ensaios e as apresentações. Com isso, estabelece-se uma relação mediada pela escrita e pela leitura da palavra, possibilitando que os participantes atribuam significados às músicas, e, dessa maneira, as relacionem também ao contexto em que estão inseridos.

Diante do exposto, elabora-se a hipótese de que as práticas e os eventos de letramento realizados pelo bloco carnavalesco baiano Afoxé Filhos de Zaze, que acontecem por intermédio da música, contribuem para a construção de letramento preocupado com a realidade social, e auxiliam o grupo a elaborar reflexões acerca de questões problematizadas pelas letras das músicas. Entende-se que, a partir dessa prática social, é despertado o senso de pertencimento e reconhecimento das identidades afrobrasileiras do grupo. Dessa forma, sustenta-se que, por via da música, o Afoxé Filhos de Zaze realiza uma intervenção de letramento em uma perspectiva intercultural.

\section{Letramento e contexto social}

Diante das preocupações sobre o "futuro do letramento", Street (2014) atenta para a seguinte questão: quais são as consequências da aquisição do letramento para os grupos sociais e a sociedade como um todo? Segundo ele, as agências de pesquisas que tentam introduzir o letramento em sociedades onde ele não é difundido, em geral, dão ênfase aos problemas técnicos de aquisição de letramento que refletem um modelo de letramento dominante, que ele denomina autônomo, que pressupõe uma única direção, associado ao progresso, civilização, liberdade individual e mobilidade social.

Essa abordagem pressupõe que as consequências sociais do letramento são pontos pacíficos - maiores oportunidades de empregos, mobilidade social, vidas mais plenas etc. - que as agências precisam decidir é como o letramento deve ser transmitido. Ela, porém, lida com um excesso de falsas obviedades em relação às implicações sociais na aquisição do letramento: há outras questões que precisam ser enfrentadas antes das questões aparentemente técnicas, questões de um modelo alternativo, "ideológico", de letramento (STREET, 2014, p. 43).

Segundo o autor (2014), diferentes problemas devem ser enfrentados através do outro modelo de letramento, designado por ele de modelo "ideológico", que se concentra em práticas sociais específicas de leitura e escrita, a exemplo da prática 
musical realizada pelo Zaze que, através das letras, promovem o letramento por meio da discussão de questões referentes à sua realidade a partir das ideologias do grupo.

O modelo ressalta a importância do processo de socialização na construção do significado do letramento para os participantes e, portanto, se preocupa com as instituições sociais gerais por meio das quais esse processo se dá, e não somente com as instituições pedagógicas (STREET, 2014, p. 44).

Nessa perspectiva, realizam-se práticas de letramentos em espaços não formais de aprendizagens, como espaço cultural, situado no Bairro Quidé, Juazeiro-BA, criado pelo Afoxé Filhos de Zaze que, mesmo sem configurar-se em uma instituição formal de ensino, usa a escrita para a construção de novos significados pela prática social e cultural. Contudo, no modelo de letramento dominante, para além dos traços óbvios do modelo colonial de transmissão de letramento, é importante, de acordo com Street (2014) levar em consideração que existem relações de poder dentro do próprio grupo, ou seja, que existe algum grau de "dominação interna".

As dimensões primárias dessa nova estrutura de poder implicam a hegemonia das áreas urbanas sobre as rurais, dos homens sobre as mulheres e das elites centrais sobre as populações locais. Para compreender os processos de transmissão de letramento nesses contextos, não basta simplesmente analisar o papel do colonialismo ou neocolonialismo; também é necessário desenvolver modos de conhecer as estruturas de poder e as culturas locais (STREET, 2014, p. $53)$.

Podem-se apontar, no caso específico do bloco Afoxé Filhos de Zaze, diversas relações de poder que obedecem posições hierárquicas familiares (o mais velho tem a primeira fala), pautadas pelas tradições do Candomblé, visto que, para o grupo, o Zaze é também mais uma extensão do terreiro. Assim, a família Rosa expõe que a ausência do senhor Manoel é apenas física, pois, espiritualmente ele se faz presente. Visualiza-se logo na entrada do terreiro Onyndacor, sede do grupo, um banner com a imagem do patriarca com a seguinte epígrafe: “A mão segura de um pai nos faz andar pelos caminhos da vida". Constata-se também que o corpo musical do bloco é, predominantemente, formado por homens, produzindo uma hegemonia do gênero 
masculino no bloco, uma realidade no percurso histórico das tradições culturais populares.

\section{Perspectivas interculturais do letramento}

Street (2006) examina os usos e significados do letramento em outros lugares e épocas, discute o letramento contemporâneo em uma perspectiva mais ampla, que desafia algumas suposições dominantes sobre letramento na própria cultura, contempla o letramento em espaços sociais outros, além da escola, e, ainda, situa as práticas de letramento no contexto social amplo, pois, de acordo com o autor:

Precisamos começar, acredito, tentando tomar consciência da linguagem que usamos e das perguntas que fazemos. O poder de definir e de nomear é em si mesmo um dos aspectos essenciais dos usos de letramento, de modo que precisamos ser ainda mais cuidadosos acerca dos termos ao abordar o próprio letramento (STREET, 2006, p. 465-466).

Quando acontecem práticas de letramento em espaços sociais como as realizadas no Afoxé Filhos de Zaze, observa-se também uma relação entre letramento e identidade, apontada por Street (2006, p. 466): "O que quero dizer com isso é que, quaisquer que sejam as formas de leitura e escrita que aprendemos e usamos, elas são associadas a determinadas identidades e expectativas sociais acerca de modelos de comportamentos e papéis a desempenhar". Nesse sentido, o letramento que acontece na interação entre escrita e leitura das músicas que fazem parte do repertório, produz noções de mundo acerca da condição desse grupo formado por jovens negros e negras residentes em bairro periférico e praticantes do Candomblé.

Os dados interculturais, portanto, sugerem que a "noção de pessoa sustentada na sociedade é inevitavelmente complexa e ambígua" e diferentes facetas da pessoa são invocadas para diferentes propósitos e contextos. Apesar dessa variação, porém, num dado meio social "os construtos de pessoas retêm um núcleo de valores e significados para os participantes sociais" (STREET, 2006, p. 468).

De acordo com o autor, os letramentos são associados a diferentes pessoas sociais e, portanto, as práticas de letramento são constitutivas de pessoalidades, 
fornecendo bases para compreender e comparar as práticas de letramento em diferentes culturas. Street (2006) também aponta os letramentos como lugares de negociação e transformação.

Street (2006) propõe alguns caminhos de pesquisa para se estudar as práticas de letramento em contextos culturais e ideológicos diversos: começar a pensar as práxis onde as pessoas estão compreendendo os significados e usos culturais das práticas de letramento; traçar programas e campanhas com base nela; ligar a teoria que é desenvolvida nos novos estudos de letramento com a experiência e os insights dos profissionais praticantes-professores, facilitadores, animadores que vêm trabalhando no campo do letramento e que tem muito a ensinar acerca das necessidades e desejos das pessoas nessa área.

\section{Metodologia}

Conforme exposto, Street (2006) aponta alguns aspectos para o "futuro do letramento"; segundo ele, seria necessário aplicar os métodos etnográficos pensando nos diferentes letramentos, atualmente praticados e vivenciados, por pessoas de diferentes backgrounds sociais e culturais, deixando de impor sobre a prática local um modelo único, uniforme e "autônomo", pois, de acordo com o autor, a pesquisa etnográfica sugere que os letramentos locais são demasiadamente substanciais para serem simplesmente "acomodados" em um único modelo.

Assim, este artigo se apoia na pesquisa qualitativa de cunho etnográfico com base em uma descrição do objeto de análise a partir do registro de informações e dados em diário de bordo com anotações realizadas durante observação propiciada pela visita ao local, de práticas realizadas no espaço cultural, como festas, apresentações, ensaios e reuniões e outras ações relacionadas ao contexto do grupo, a fim de conhecer como acontecem os eventos e as práticas de letramento nesse contexto.

\section{Os filhos de Zaze}

O bloco Afoxé Filhos de Zaze surge no cenário cultural juazeirense em novembro de 2011, inicialmente, com o desejo de prestar uma grande homenagem ao patriarca Manoel Rodrigues Rosa, que era do Axé, também grande folião da festa de 
momo. O objetivo era realizar um projeto artístico que envolvesse a comunidade e o povo de santo que compõem os terreiros: Ylê Asé Ayrá Onyndancor, Ylên Asé Omym Kayodéo e Bandalekongo, localizados no bairro Quidé na cidade de Juazeiro-BA.

Considerado pelos moradores como um grande quilombo urbano, a população do bairro Quidé é formada, em sua grande maioria, por negros e negras; há predominância das religiões de matriz africana, fato perceptível pelos diversos terreiros de Candomblé. É nesse bairro que se consolida um bloco carnavalesco composto por jovens afrodescendentes, o Afoxé Filhos de Zaze. Logo depois, o Afoxé torna-se um espaço cultural de formação e desenvolvimento artístico, tendo como fio condutor a música de terreiro com os pés fincados no Candomblé.

No espaço cultural do Zaze, além dos ensaios do bloco, também acontecem oficinas de artes e de criação e confecção de fugurinos. No espaço, também acontecem festas como o concurso que escolhe a musa negra do bloco, a festa de boiadeiro e a festa de guerreiro. Nas festas, o Afoxé vende bebidas e comidas e as receitas decorrentes dessas vendas são investidas no bloco e na manutenção do espaço. Nos últimos anos, o Afoxé tem feito parcerias com o Serviço Social do Comércio (SESC), em Petrolina (PE), sendo esse espaço um polo do já consolidado Festival Aldeia do Velho Chico.

Filhos de Zaze foi o nome escolhido para batizar o bloco carnavalesco, que, na língua banto de Angola, quer dizer Xangô, um deus do reino de Oyó, divindade do fogo, do trovão e da justiça. Xangô também era o Orixá do senhor Manoel Rosa, inspiração para a criação do bloco. Florisvaldo Rosa, um dos filhos, ressalta a importância do terreiro e dessa divindade regente: “(...) a nossa relação com o terreiro Onyndancor é a melhor de todas, pois, ele é o terreiro do nosso pai, Xangô, nossa fonte de inspiração e onde nós buscamos toda a energia pelos nossos direitos e enfrentamos o dia a dia" (ROSA, 2018).

Percebe-se que o Afoxé Filhos de Zaze já nasce com a benção de Xangô, um dos Orixás mais cultuados nos terreiros de Candomblé no Brasil, mas, também, com outra grande missão que é a de levar para as ruas do carnaval de Juazeiro-BA a cultura negra, através dos batuques, tambores e ritmos dos terreiros. Nessa lógica, a transposição do Candomblé para as ruas, durante o carnaval, significou também a tomada de uma posição política diante de uma sociedade excludente que via nas manifestações culturais africanas um atraso cultural (SANTOS, 2010). 
Em relação ao repertório, esse é construído em parceria entre os componentes Florisvaldo Rosa, Matheus e Waldery, cantores do Afoxé Filhos de Zaze e, em seguida, é apresentado aos demais integrantes para aprovação. No entanto, mesmo diante do aval de todos e todas que compõem o Zaze, ainda assim, deve-se pedir permissão aos Orixás, um ritual necessário para que a nova música seja inclusa nas apresentações. Nesse sentido, ressalta-se que existe sempre um diálogo entre as forças ancestrais que estiveram antes e se foram com os presentes que continuam no espaço terreno.

A formação de um bloco de Afoxé torna-se um ato político, uma vez que a sua presença vibrante nas ruas amplia a visibilidade das tradições do povo negro, herança dos seus ancestrais que chegaram ao Brasil escravizados. "O afoxé pode ser considerado uma marca sociocultural do negro na Bahia e fruto de uma herança cultural dinâmica, em permanente processo de transformação e ressignificação" (BARBOSA, 2010, p. 28). Por esse ângulo, se movem para as avenidas os rituais do povo de terreiro, possibilitando a exaltação da beleza dessa cultura que tem cor, e é preta.

O Afoxé Filhos de Zaze realizou em 2012 um marco histórico no cenário cultural da cidade, ao se tornar o primeiro grupo de negros a sair no Carnaval oficial de Juazeiro-BA, levando junto a tradição do povo de santo e a comunidade do Quidé que, em tempo recorde, conseguiu se organizar, viabilizando parcerias na realização desse que é seu grande projeto. Assim, em poucos meses, após o primeiro ensaio, com a licença de Xangô e as bênçãos de todos os Orixás, o Zaze, oficialmente, sai na avenida, carregando com ele a memória de Manoel Rosa e, dando continuidade ao legado do mestre.

\section{Interculturalidade dos afoxés}

Os afoxés são expressões culturais que surgiram na Bahia no final do século XIX, quando clubes negros tinham uma organização carnavalesca formalizada, passando a receber solicitações diversas, com diferentes visibilidades. Essa história também foi marcada por forte tensão diante da proibição de elementos do Candomblé e da cultura negra na época. A história dessa manifestação cultural destaca-se também no contexto da capital baiana, o Afoxé Filhos de Gandhi, que serviu de referência para a formação do bloco juazeirense que há cinco anos desfila no carnaval da cidade. 
A definição etimológica para afoxé é múltipla, primeiro porque os estudiosos que observaram seus desfiles no século XIX não deixaram registros concisos quanto à denominação do termo. Segundo, por se tra tar de um termo de ampla abrangência conceptiva. Afoxé é uma manifestação carnavalesca composta pelo ritmo ijexá, cânticos, indumentárias, instrumentos musicais e ritual. Todos esses itens, conjuntamente, formam o que chamamos de Desfile de Afoxés, cortejo de rua que sai durante o carnaval (BARBOSA, 2010, p. 13).

De modo geral, dentro de um painel histórico da cultura negra, os desfiles de afoxés eram pouco valorizados, sendo vistos pela sociedade apenas como um momento festivo com pouco reconhecimento e sem valorização; o que nos permite perceber que essa atitude de negar visibilidade para ações de afirmação e de empoderamento de grupos historicamente rechaçados como o povo negro sempre existiram.

No entanto, no caso do Afoxé Filhos de Zaze, a presença do bloco no carnaval de Juazeiro-BA foi recebida com muita alegria pela sociedade, sinalizando sua expressão nesse cenário multicultural. Na comunidade do Quidé, o bloco também é muito respeitado, pois reconhece-se a importância do Zaze no fortalecimento cultural da região. O Blog de Parlim - Arte Educação publicou, na época, em sua página as seguintes manchetes:

Os Filhos de Zaze mostram alegria, tradição, trazendo uma mensagem de Paz ao nosso carnaval; O bloco nasceu nos terreiros de candomblé, dos bairros Quidé e Palmares; O Afoxé saiu na avenida irradiando beleza, paz e alegria; O carnaval de Juazeiro ganha um tesouro com a participação da cultura brasileira (BLOG PARLIM, 2012).

A multiculturalidade é uma característica da cultura brasileira e está presente no carnaval e em diversas manifestações artísticas, possibilitando o encontro plural entre culturas. Porém, no Brasil aponta-se uma configuração muito peculiar, visto que a colonização do país foi bastante traumática, desenvolvendo-se pela mão violenta do europeu que aqui aportou e que resultou na eliminação física e na escravização do "outro", do diferente, do exótico, produzindo, ao longo dos séculos, diversas formas de exclusão de direitos e, consequentemente, a negação de alteridade. Nessas condições, uma educação para a alteridade não pode nunca se concretizar, como apontam Santiago, Akkari e Marques (2013): 
A perspectiva multicultural se configura em uma proposta de "educação para a alteridade" aos direitos do outro, à igualdade de oportunidades, uma proposta democrática mais ampla que, no mundo anglo-saxão, define-se como educação multicultural e que nos países europeus, assume diferentes denominações; pedagogia do acolhimento, educação para a diversidade, educação comunitária, educação para a igualdade de oportunidades ou, simplesmente, educação intercultural (SANTIAGO; AKKARI; MARQUES, 2013, p. 21-22).

Com isso, os processos educativos no país foram sendo estruturados pela lógica da homogeneização cultural e não pela diversidade, tendo como referência uma cultura ocidental, branca, letrada, mais especificamente, uma cultura eurocêntrica, que, na busca pela expansão de seu domínio, silenciou vozes, saberes e culturas de determinados grupos, como os indígenas e os negros escravizados trazidos para o país. Em relação à educação, os autores afirmam que: “A educação intercultural no Brasil está situada diante das hierarquizações sociais, e o mais complexo problema a ser enfrentado é reconhecer as diferenças e as integrá-las a um contexto que não as anule" (SANTIAGO; AKKARI; MARQUES, 2013, p. 23).

Entende-se a interculturalidade numa perspectiva crítica, capaz de produzir identidades e emergir de dentro das relações, entre diferentes culturas. Mesmo percebendo os arcabouços de dominação da cultura hegemônica, tradições culturais como os afoxés, herança dos africanos, abriram espaços para relações interculturais com as estruturas de poder, encontrando na interação outros modos de existir e, assim, evitando o apagamento total. Nesse raciocínio, sair às ruas por intermédio de blocos carnavalescos, levando a música de terreiro significava para os afoxés encontrar espaços para continuar resistindo, utilizando o próprio espaço da outra cultura: foi essa a estratégia encontrada pela cultura dita "inferior" para não sucumbir diante da cultura dita "superior".

Nesse sentido, as músicas compostas pelo Afoxé Filhos de Zaze são inspiradas em pontos e toques dos terreiros de Candomblé que, na cultura africana, são essencialmente orais. Entretanto, no Brasil, com a colonização e a influência da cultura letrada europeia, tais pontos e toques passaram a ser escritos e partiturados. Isso posto, as músicas do Afoxé Filhos de Zaze propõem esse encontro entre culturas, na medida em que promovem um trânsito entre a tradição oral e a escrita. Nesse encontro, há, 
todavia, uma hegemonia da cultura letrada e branca sobre a cultura oral e negra, mas, apesar de existir uma grande tensão entre as duas, essa última não perde sua identidade, pois se relaciona com a outra cultura de forma que busca um olhar crítico, encontrando na própria relação maneiras de se fortalecer.

Ao analisar a música intitulada $E$ a luta do Zaze:

"Sua luta pela Paz, igualdade e muito axé.

Salve o povo de terreiro e simpatizantes do Candomblé!

Olhe o Zaze ê... olhe o Zaze á... olhe o Zaze ê, mayongolê, mayongolá

Nos 3 versos da composição acima, a recorrência das palavras de cultura e antirracistas, tais como, "axé”, "povo de terreiro", “candomblé”, "mayongolê", "mayngolá", sintetiza as lutas do povo negro pela igualdade racial e pela paz, a necessidade de afirmação da religião praticada pelo grupo, que apesar de alguns avanços ainda é marginalizada e, portanto, necessitando de reconhecimento. Assim, é por meio do letramento possibilitado pela escrita e pela leitura da letra da música $E$ a luta do Zaze que se pode ampliar o debate sobre temas recorrentes no contexto e que envolvem e afetam os integrantes do grupo, como preconceito racial e intolerância religiosa.

Assim, a partir do encontro intercultural, utiliza-se a própria estrutura opressora para questionar a opressão, usando o letramento ideológico como estratégia para discutir temas como racismo e intolerância religiosa. Apesar da percepção de que existem avanços proporcionados pelas ações afirmativas em prol de minorias, como as cotas para entrada de negros e negras nas universidades e também em concursos públicos, ainda é muito visível a necessidade de mais intervenções pelo Estado:

A constituição afirma ainda, que o Estado garantirá a todos o pleno exercício dos direitos culturais e acesso às fontes da cultura nacional, apoiará e incentivará a valorização e a difusão das manifestações das culturas populares, indígenas e afro-brasileiras. A ênfase na valorização cultural dos grupos culturalmente marginalizados, ao nosso entender, explicita a necessidade de transformar o cenário de exclusão, a fim de garantir os princípios democráticos expressos no documento, porém, em termos práticos e concretos, essa situação não se consolida, determinando a necessidade de outras intervenções no campo legal e nas políticas públicas para efetivação de tais processos 
democráticos e de participação de todos (SANTIAGO; AKKARI; MARQUES, 2013, p. 24).

Dessa maneira, interpreta-se que há bastante o que se fazer em tempos de intolerância e preconceitos, males que estruturam a sociedade assolando as instituições educacionais. Portanto, é importante fazer maiores incursões no combate e na defesa de direitos, visto que, a “(...) ação afirmativa que não enfatiza a luta contra as desigualdades é inócua" (SANTIAGO; AKKARI; MARQUES, 2013, p. 24). Nessa perspectiva, o letramento realizado pela música do Afoxé Filhos de Zaze torna-se um instrumento de ação. Uma ferramenta de transformação social que pode, ao lado de outras políticas afirmativas, contribuir para a garantia de direitos básicos que foram negados, historicamente, pelo Estado aos negros e negras.

\section{Considerações finais}

A relação mediada pela leitura e a escrita através da música vem propiciando aos integrantes do Afoxé Filhos de Zaze um letramento intercultural e ideológico. Nesse aspecto, através de práticas de letramento, amplia-se para o grupo a história do povo negro, relacionando-a com a realidade local vivida e a própria história da tradição dos povos de terreiros.

Nossa pesquisa sugere que existe uma prática social realizada no espaço cultural do Afoxé Filhos de Zaze que é mediada pela música e que, nesse contexto, se configura como letramento ideológico em uma perspectiva intercultural. Sugere, também, que essa ação cultural contribui para o fortalecimento da luta de resistência política do grupo vivendo em uma sociedade estruturalmente racista. Nesse sentido, faz-se extremamente relevante a participação do Zaze em eventos culturais como a histórica participação em 2012 no Carnaval de Juazeiro-BA, pois, sua presença, além de visibilizar a cultura dos povos afrodescendentes é um ato de resistência.

Dessa maneira, observa-se na análise da música É a luta do Zaze que a letra composta pelo grupo narra histórias de lutas, suscita memórias e problematiza questões relativas ao racismo e intolerância religiosa acentuadas neste contexto de comunidade negra e periférica que é o bairro do Quidé em Juazeiro-BA. Nos cortejos pelas ruas da cidade, o grupo executa um repertório inspirado em pontos e toques de Candomblé que 
são saudações que invocam os Orixás, pedindo licença e proteção aos ancestrais, acentuando, assim, os objetivos do grupo de afirmação da cultura negra.

Conclui-se, portanto, que o letramento realizado pelo Afoxé Filhos de Zaze tem relevância, pois exerce uma prática musical ideológica configurando-se em ação política com potência de quebrar paradigmas, a exemplo de levar a música produzida nos terreiros de Candomblé ao polo principal do carnaval de Juazeiro-BA, assim, transmutando para as ruas as tradições de matrizes africanas. Portanto, por meio da música é possível reverenciar e exaltar a cultura negra, desmistificando crenças e minimizando preconceitos em relação aos povos de terreiros.

\section{Referências bibliográficas}

BARBOSA, Magnair. Pesquisa Histórica. In: Desfile de Afoxés. BAHIA, Governo do Estado. Secretaria de Cultura. IPAC/Salvador: Fundação Pedro Calmon, IPAC, 2010.

BLOG DE PARLIM. Arte Educação, 2012. Disponível em: <http://parlim.blogspot.com/2012/02/afoxe-filhos-de-zaze-carnaval-de.html>. Acesso em: 11 jul. 2018.

ROSA, Florisvaldo. Afoxé Filhos de Zaze [entrevista concedida a] Jailson de Lima Silva. Petrolina, 2018.

SANTIAGO, Mylene Cristina; AKKARI, Abdeljalil; MARQUES, Luciana Pacheco. Educação intercultural: desafios e possibilidades. Petrópolis: Vozes, 2013.

SANTOS, Nívea Alves dos. Pesquisa Etno-histórica. In: Desfile de Afoxés. BAHIA, Governo do Estado. Secretaria de Cultura. IPAC/Salvador: Fundação Pedro Calmon, IPAC, 2010.

STREET, Brian. Perspectivas Interculturais sobre o letramento. Filologia e linguística portuguesa. USP. V. 18. 2006, p. 465- 488.

STREET, Brian. Letramentos sociais: abordagens críticas do letramento no desenvolvimento, na etnografia e na educação. Letramento e mudança social: a importância do contexto social no desenvolvimento de programas de letramento. Trad. Marcos Bagno. São Paulo: Parábola Editorial, 2014. 